\title{
Sounds perceived as annoying by hearing-aid users in their daily soundscape
}

\author{
Asa Skagerstrand, Stefan Stenfelt, Stig Arlinger and Joel Wikstrom
}

\section{Linköping University Post Print}

\section{Tweet}

N.B.: When citing this work, cite the original article.

Original Publication:

Asa Skagerstrand, Stefan Stenfelt, Stig Arlinger and Joel Wikstrom, Sounds perceived as annoying by hearing-aid users in their daily soundscape, 2014, International Journal of Audiology, (53), 4, 259-269.

http://dx.doi.org/10.3109/14992027.2013.876108

Copyright: Informa Healthcare

http://informahealthcare.com/

Postprint available at: Linköping University Electronic Press

http://urn.kb.se/resolve?urn=urn:nbn:se:liu:diva-106015 


\section{Sounds perceived as annoying by hearing aid users in their daily soundscape}

Åsa Skagerstrand ${ }^{\mathrm{a}, \mathrm{c}}$, Stefan Stenfelt ${ }^{\mathrm{b}, \mathrm{c}}$, Stig Arlinger ${ }^{\mathrm{b}, \mathrm{c}}$, Joel Wikström ${ }^{\mathrm{a}}$.

${ }^{\mathrm{a} S}$ School of Health and Medical Sciences, Örebro University, Örebro, Sweden

${ }^{\mathbf{b}}$ Division of Technical Audiology, Department of Clinical and Experimental Medicine,

Linköping University, Linköping, Sweden

${ }^{c}$ Linnaeus Centre HEAD, Swedish Institute for Disability Research, Department of

Behavioural Sciences and Learning, Linköping University, Sweden

Keywords: Soundscape, annoying sounds, hearing aid, hearing aid fitting

Corresponding author:

Stefan Stenfelt, Department of Clinical and Experimental Medicine, Linköping University, 58185 Linköping, Sweden.

E-mail: Stefan.stenfelt@liu.se 


\begin{abstract}
Background: The noises in the modern soundscapes continue to increase and are a major origin for annoyance. For a hearing impaired person, a hearing aid is often beneficial but noise and annoying sounds can result in non-use of the hearing aid, temporary or permanently.
\end{abstract}

Objective The purpose of this study was to identify annoying sounds in a daily soundscape for hearing aid users.

Design A diary was used to collect data where the participants answered four questions per day about annoying sounds in the daily soundscape over a two-week period.

Study sample Sixty adult hearing aid users.

Results Of the 60 participants $91 \%$ experienced annoying sounds daily when using hearing aids. The annoying sound mentioned by most users, was verbal human sounds, followed by other daily sound sources categorized into 17 groups such as TV/radio, vehicles, and machine tools. When the hearing aid users were grouped in relation to age, hearing loss, gender, hearing aid experience, and type of signal processing used in their hearing aids, small and only few significant differences were found when comparing their experience of annoying sounds.

Conclusions The results indicate that hearing aid users often experience annoying sounds and improved clinical fitting routines may reduce the problem. 


\section{Introduction}

The experience of the environment consists of a mixture of sensory inputs, e.g. tactile, visual, and auditory input. Schafer (1994) used the term soundscape as a designation for the auditory experience of the acoustic environment. Augoyard et al (1999, p131) defined soundscape, with origin in Schafer's term, as "the totality of sound phenomena that lead to a perceptual, aesthetic and representational comprehension of the sonic world." Soundscape has also been defined as the sounds that colour the landscape and also are coloured by the landscape (Hedfors, 2003). In what follows, the definition of Augoyard et al (1999) soundscape will be used.

In soundscapes of today, noise is a major origin of annoyance (Raimbault \& Dubois, 2005). Noise is here defined as unwanted, often complex, sounds in our soundscape and annoyance caused by sound (or noise) is a negative psychological effect when listening, or exposed to a soundscape. According to a literature review by Guski et al (1998), the level of annoyance can be ascribed to five factors. In their description the level of annoyance is 1) based on, or caused by an emotion, a sense of unpleasantness, 2) a result of disturbance, the noise is masking the target signals, 3) based on an attitude, a person's attitude towards the sound source or situation affect the level of annoyance, 4) based on knowledge, awareness and familiarity of the sound source affects the sense of annoyance, 5) a result of a rational decision, handling an annoying situation in a rational way reduces the level of annoyance. Consequently, the level of annoyance cannot always be ascribed to one single entity. However, the two first items, unpleasantness and masking, indicates that from an acoustical point of view, annoyance can be caused by the acoustical pattern of a sound that is unpleasant per se or, affect the sound perception or situation negatively. As a result, unwanted sounds can cause negative effects in form of pure acoustic annoyance (unpleasantness) and informative annoyance (masking of the 
target). In what follows, annoying sounds are defined as sounds that have a negative effect in either or both of these aspects.

A sensorineural hearing impairment is associated with recruitment, reduced frequency selectivity, and poorer speech perception, particularly when the signal-to-noise ratio is poor (e.g. Moore, 2002; Buus \& Florentine, 2001). The overall aim of the audiological rehabilitation is to give the hearing impaired person means and strategies to cope with the hearing impairment, and the final result of the rehabilitation often show psychosocial effects, such as less feeling of stigmatisation, increased engagement in social activities, and improved quality of life (Kochkin \& Rogin, 2000; Hallberg et al, 2008). As part of audiological rehabilitation, the hearing impaired person can be fitted with one or two hearing aids (e.g. Dillon, 2001; Smeds \& Leijon, 2000). The primary aim of a hearing aid is, based on the individual hearing loss, to provide the hearing impaired person an audible signal by the gain in the hearing aid. In addition, modern hearing aids also compensates to some extent for suprathreshold deficits using compression, division in multiple frequency-bands, and signal processing strategies to enhance the desired signal (speech) or decrease the unwanted sound (noise), often differently in different acoustical environments (Dreschler et al, 2008).

Even if usage of hearing aids increases the opportunity of participation (Turner \& Cummings, 1999; Kochkin \& Rogin, 2000) they can also introduce problems that eventually result in a non-usage of the hearing device (Kochkin, 2000; Kochkin 2010; Linssen et al, 2013). In the Kochkin (2000) study 32 different reasons for not wearing hearing aids are listed, where listening in groups and in noise are the two most problematic situations for hearing aid users. One problem with hearing aids is that in order to provide audibility to the hearing impaired person, the hearing aid output may be too loud at high input levels. Killion (1993) indicates 
the necessity of hearing aids being designed and fitted to handle high input levels that are common in the daily soundscape. For example, according to Killion (1993), the sound levels can reach $80-100 \mathrm{~dB}(\mathrm{~A})$ in a common church sermon. Moreover, the sound levels vary during the sermon indicating that the hearing aid need adjustments for optimal performance. When fitting hearing aids it is desirable to verify that the output from the hearing aid does not produce uncomfortable high levels at loud sound input (e.g. Dillon, 2001). This is important for overall pleasantness of the sound but also according to the study by Smeds et al (2006), where they report that persons with hearing impairment, in general, prefer less overall loudness than given by most prescription rules. Accordingly, hearing aid users prefer less gain than that derived by ordinary hearing aid prescriptions that aim at optimizing speech perception, and the gain of the fitted hearing aid may cause annoyance at situations with sounds of high levels even if the hearing aid fitting is conducted according to normal clinical routine.

Modern digital hearing instruments offer significant advantages compared to earlier devices, increasing the overall satisfaction of hearing instrument usage (Kochkin, 2005). One of those advantages of the hearing aid is the improved ability for understanding speech in noise (e.g. Alcantara et al, 2003, Hällgren et al, 2005, Kirkwood, 2001). Modern hearing aids include, for example; directional microphones, multi-band wide-dynamic range compression (WDRC), noise reduction, environmental classification, and multi-programs. The benefit of hearing aid use in dynamic listening situations has been assessed previously and some of these studies indicate the varying degrees of benefit in different situations, for most hearing aid users. The benefit is related to the possibility to achieve improved speech understanding and identification of various acoustic cues (e.g. Gatehouse et al, 2003; Gatehouse \& Akeroyd, 
2006; Noble \& Gatehouse, 2006). In the evaluation of a hearing aid fitting, self-report data from the patient forms an essential part.

These data focus primarily on the improved speech recognition with the hearing aids (e.g. Cox et al, 2007), but rarely assess aspects of sound quality, disturbance or annoyance. For example, the widely used APHAB (Abbreviated Profile of Hearing Aid Benefit) questionnaire (Cox \& Alexander, 1995) includes aversiveness of sounds as one of four main dimensions assessed, but does not gather in-depth information into this aspect even if the general finding is that aided listening increases the aversiveness of sounds.

Some previous studies have tried to describe the human perception of the urban soundscape (Yang \& Kang, 2005; Raimbault et al, 2003; Kawai \& Yano, 2002). These studies report that (1) most people have difficulties describing their own soundscape and (2) sounds that are perceived as disturbing and causing annoyance exist in the daily environment. The work by Raimbault et al (2003) indicates that there is a lack of information about the perception of everyday urban sounds, and they suggest that more thorough studies of the topic should be conducted. With regard to hearing-impaired persons, information of their perception of everyday urban sounds seems even rarer. The studies mentioned above did not consider the possibility of hearing impairment in the description of soundscape and the specific problems that occur related to hearing. But, as stated by Noble: people with hearing impairment are "real people striving to cope in the real audible world" (Noble, 1983, p326).

If the problems with loudness, speech perception, and frequency selectivity are considered, it seems plausible that persons with hearing impairment, fitted with hearing aids, suffer from annoying sounds more than normal-hearing persons do since the hearing aid amplifies most 
sounds. However, the use of compression, directional microphones or noise reduction systems may reduce the annoyance to some extent. Using digital technology, it is possible to reduce the overall loudness of the sound to a hearing aid user, in line with the suggestion of Smeds et al (2006).

There are studies indicating that hearing aid users and normal hearing listeners rate annoying sounds as equally annoying (Palmer et al, 2006; Keidser et al, 2007; Keidser et al. 2008). When the annoyance was rated for traffic sounds and dining sounds in a laboratory environment, unaided hearing-impaired persons perceived less annoyance than the normalhearing persons did (Palmer et al, 2006). However, when the hearing-impaired persons used hearing aids with digital noise reduction systems, they rated the annoyance similarly as the normal hearing persons did. Hermandez et al (2006) found that for new wearers of hearing aids, transient noises were equally annoying as noises of longer duration.

At high enough levels, normal-hearing persons find urban sounds annoying (the loudness level for experiencing annoyance is source dependent, Kawai \& Yano, 2002). Moreover, it has been reported for normal-hearing persons that sound with music-like temporal structure can become annoying when intruding the living environment (Botteldooren et al, 2006). Even though it is probably true for hearing-impaired persons as well, we are not aware of any studies indicating if it is valid for persons with hearing impairment.

An ecological approach of everyday listening in a daily soundscape is based on the experience of listening to events rather than listening to sounds (Gaver, 1993). Hearing an event is the result of an interaction between a given sound-generating object and a given environment that causes an experience of the event (Raimbault \& Dubois, 2005). This interaction and the 
possibility to share hearing events improve the participation which is a requirement for good health (WHO, 2001). For a person with a hearing-impairment, the possibility of sharing hearing events and participation in the society are restricted, often due to noise and annoying sounds, since their ability to perceive speech in noise is worse than for persons with normal hearing. Moreover, investigations of the soundscape that is valid for the hearing impaired population cannot be solely based on a general population. It is desirable to increase the knowledge of hearing-impaired persons' and hearing aid users' experience of various soundscapes. Kawai \& Yano (2002) showed that the perception of sound is different in a laboratory environment compared with a field study. In their study, sounds in their true environment were judged more positive and comfortable than the same sounds in the laboratory. Consequently, as stated by Kawai \& Yano, laboratory results cannot be directly applied to the conditions of real life, and there is a need of studies of real life conditions. Also, in order to improve the benefit of hearing aids it is important to know which sounds the hearing aid users find most annoying. Improvement for the hearing impaired person can be accomplished by improvement in the hearing aid signal processing but also by the audiologist's information to, and counselling of, the hearing-impaired person.

The aims of the current study are twofold. The primary aim is to describe sounds and sound sources that hearing aid users find annoying in their everyday soundscape. A secondary aim is to investigate if personal or hearing aid related factors (age, hearing loss, gender, hearing aid experience, signal processing) can predict the hearing aid users' experience of annoyance from specific sounds. 


\section{Material and method}

\section{Participants}

From the archive of the audiological clinic at Örebro university hospital, Sweden, potential participants were identified. First, five days of every month (between 1 and 31) were randomly selected. In the patient archive of the clinic every $10^{\text {th }}$ person's file, ordered by date of birth, born on these randomly obtained days, were selected. Those who fulfilled the inclusion criteria were invited to participate in the study. The inclusion criteria were: (1) acquired sensorineural sloping ${ }^{1}$ hearing loss (irrespective of degree of hearing loss), (2) age between 16 and 85 years, and (3) fitted with hearing aids either during the last three months or more than twelve months ago, (4) completed successful rehabilitation ${ }^{2}$. Through this procedure 400 hearing-impaired persons that fulfilled the inclusion criteria were invited to participate in the study. Of these 68 accepted to participate. Eight of the recruited participants did not finish the study. The participants who did not complete the study represented both male and female, both younger and elderly persons, different hearing aid experience, and different types of signal processing in their hearing aids. Reasons for not completing the study were difficulties to verbalise annoying sounds or a too time-consuming method with both active listening and writing. In addition, some stated health or family reasons for not completing the study. Only data from participants completing the study were included in the analysis.

The 60 subjects who completed the study were between 44 and 82 years of age (mean age of 68 years); 21 female subjects and 39 male subjects. They all had an acquired bilateral sensorineural sloping hearing loss of various degrees (Figure 1). Pure tone average hearing threshold level for $0.5,1,2$, and $4 \mathrm{kHz}$ (PTA4) was $40 \mathrm{~dB}$ HL for the right ear and $42 \mathrm{~dB} \mathrm{HL}$

\footnotetext{
${ }^{1}$ Sloping hearing loss is here defined as a hearing loss that has a general trend of increasing with frequency.

${ }^{2}$ A rehabilitation was deemed successful when the set out goal for the rehabilitation was reached according to both patient and audiologist.
} 
for the left ear. Even if all participants have the same hearing loss configuration, their level of hearing loss (PTA4) varied between 25 and $81 \mathrm{~dB}$ HL.

Hearing thresholds hearing impaired subjects

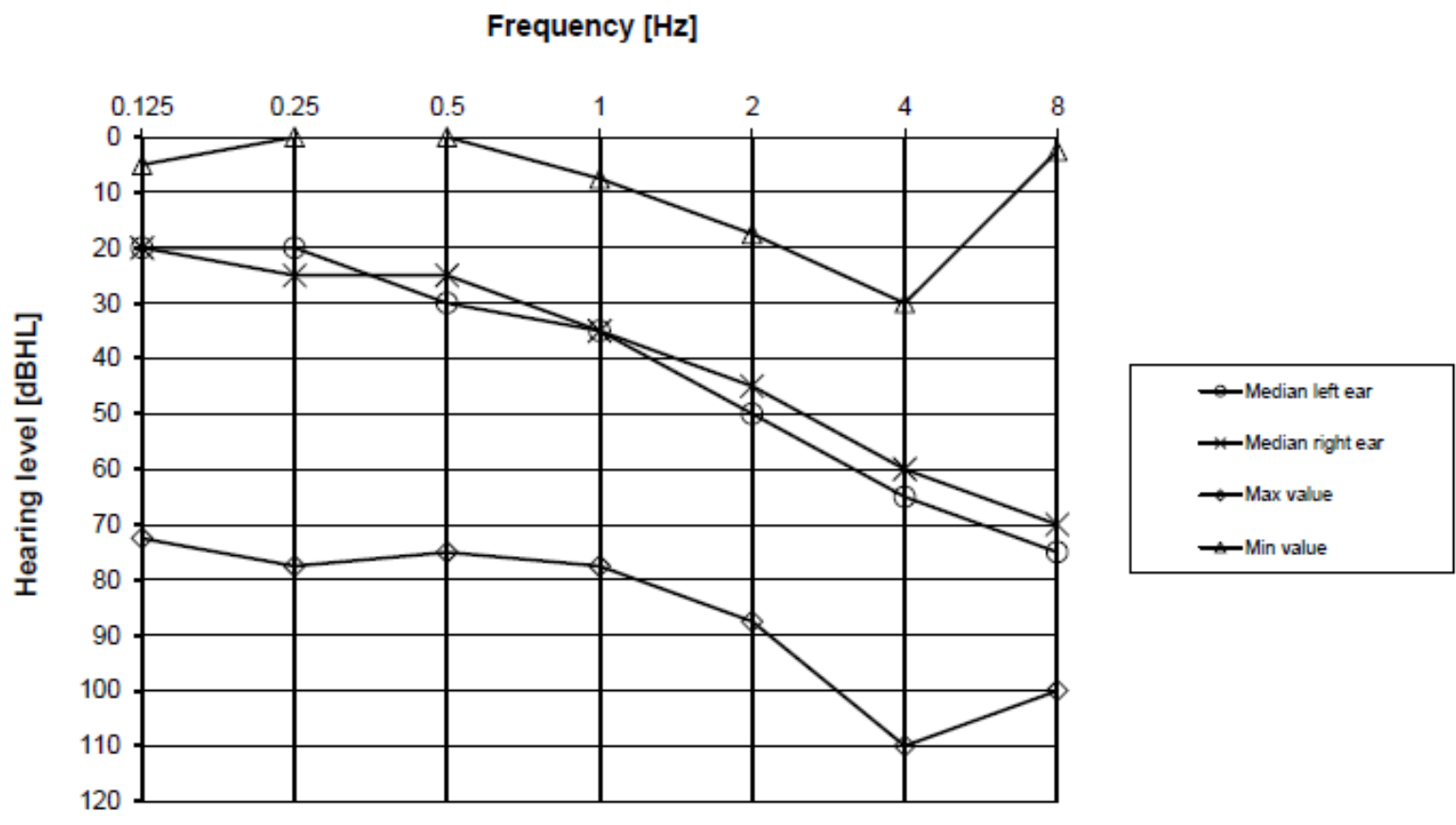

Figure 1: Average hearing threshold levels for the sixty hearing-impaired subjects participating in the study. Left ears are indicated with crosses and right ears are indicated with circles. Maximum and minimum values for each frequency are also shown in the diagram. All participants have the same pattern, but varying degree, of hearing loss.

The study population was a clinical sample, where all participants had completed the clinical rehabilitation process prior to this study. All participants were fitted bilaterally with hearing aids, but 12 subjects used only one hearing aid. The hearing aid fitting was conducted by registered audiologists at the audiological clinic, Örebro university hospital. The fitting procedure, performed by the audiologists, was based on the NAL prescriptive formula and the manufacturer's guidelines. The primary goal of the NAL prescriptive method was to maximize speech audibility and it did not consider uncomfortable levels for the hearing aid fitting. For linear hearing aids NAL-R was used while NAL-NL1 was used for the non-linear 
hearing aids. It should be noted that the NAL implementation used was the manufacturers. These may differ from the original NAL-RP and NAL-NL1 where output level can be prescribed. The gain of the hearing aids was controlled with real-ear measurements using sound levels at around $60 \mathrm{~dB}$ SPL to verify a smooth frequency-amplification function. Subjective loudness evaluations consisting of verbal judgments of perceived loudness and tests of rustling papers, speech and music from the radio, and rattling keys were performed during the fitting procedure.

No objective loudness scaling was used to verify that the hearing aids did not produce too loud outputs at high-level inputs. However, when requested by the user, the hearing aid gain was adjusted by the clinical audiologist within the normal rehabilitation process. For example, if the hearing aid user experienced high-level sounds as annoying, the gain would be reduced for the appropriate loudness, restoring as much speech understanding as possible.

Twenty of the participants were fitted with hearing aids during the last three months prior to participating in the current study, (non-experienced users). According to the clinical protocol, the non-experienced users had completed the fitting procedure but had not had their follow-up visit, which normally takes place 6-12 months after the final hearing aid fitting visit. The remaining 40 participants had used their hearing aids for at least one year (experienced users). The median time for hearing aid use was 4.5 years in this group. The hearing aids used in the study were the participants' own current hearing aids, listed in Table 1.

The hearing aids were classified as using simple (S) or advanced (A) signal processing (table 1). This classification was based on the hearing aid manufacturer's own descriptions of the signal processing and according to the classification in the study by Schum \& Pogash (2003). 
Advanced signal processing was defined as digital non-simplistic signal processing, e.g. noise reduction, speech enhancement, feedback suppression, and multi-channel wide dynamic range compression. The definition of simple signal processing was analogue or digital signal processing with similar signal processing as in analogue hearing aids. However, it should be noted that the hearing aids classified as using simple signal processing included automatic gain control in order to reduce the gain at high input levels. All subjects' patient record and hearing aid settings were controlled to ensure that the above classification of the hearing aids were correct.

Table 1. Hearing aids used in the current study, numbers of each type and classification of signal processing. $S=$ Simple signal processing,$A=$ Advanced signal processing .

\begin{tabular}{|c|c|c|c|}
\hline Manufacturer & Type & \begin{tabular}{|l|} 
Quantity \\
Persons
\end{tabular} & $\begin{array}{c}\text { Signal } \\
\text { Processing }\end{array}$ \\
\hline GNReSound & \begin{tabular}{|l|} 
BZ5 \\
Canta \\
Danalogic 163D
\end{tabular} & $\begin{array}{c}1 \\
11 \\
3\end{array}$ & $\begin{array}{l}\mathrm{S} \\
\mathrm{A} \\
\mathrm{S}\end{array}$ \\
\hline Oticon & \begin{tabular}{|l|} 
Adapto \\
Atlas \\
Digifocus \\
Ergo \\
Gaia \\
Syncro
\end{tabular} & $\begin{array}{l}2 \\
4 \\
1 \\
1 \\
1 \\
1\end{array}$ & $\begin{array}{l}\mathrm{A} \\
\mathrm{S} \\
\mathrm{S} \\
\mathrm{S} \\
\mathrm{A} \\
\mathrm{A}\end{array}$ \\
\hline Philips & M61 K & 3 & $\mathrm{~S}$ \\
\hline Phonak & Pico Forte SCD2 & 1 & $\mathrm{~S}$ \\
\hline Qualitone & TKA II & 2 & $\mathrm{~S}$ \\
\hline Sonar & \begin{tabular}{|l|}
$130 \mathrm{~K}$ \\
$240 \mathrm{DCSV}$
\end{tabular} & $\begin{array}{l}2 \\
1\end{array}$ & $\begin{array}{l}\mathrm{S} \\
\mathrm{S}\end{array}$ \\
\hline Unitron & Ikon & 7 & $\mathrm{~S}$ \\
\hline Widex & \begin{tabular}{|l|} 
A4 \\
CX+ \\
G-series \\
L8E \\
P8 \\
C8+ \\
Senso Diva \\
Senso Vita 9 \\
\end{tabular} & \begin{tabular}{l|l}
3 & \\
2 & \\
2 & \\
2 & \\
1 & \\
2 & \\
3 & \\
4 &
\end{tabular} & $\begin{array}{l}\text { S } \\
\text { S } \\
\text { S } \\
\text { S } \\
\text { S } \\
\text { S } \\
\text { A } \\
\text { A }\end{array}$ \\
\hline & 23 types & 60 & \\
\hline
\end{tabular}




\section{Data collection}

The data were collected using a diary. The diary contained the following four questions about annoying sounds in the daily soundscape (translations from Swedish):

1. What sound/sound source was annoying?

2. What characteristic of the sound was annoying?

3. In what situation was the sound annoying, and how were you occupied in that situation?

4. What did you do to reduce the annoyance?

Annoying sound was defined as:

Sound that is negatively perceived and has a negative effect in your daily soundscape. The annoying sound can be negative in one situation but not in another. The sound can be irritating or unpleasant; it can make it difficult or impossible to recognize speech. (Translation from Swedish)

It is possible to note several sound sources every day.

Prior to the main study a pilot study with 10 normal-hearing subjects (mean age 23 years) was conducted in order to verify the diary. The pilot study, including analysis, was carried out in the same way as the main study with the hearing-impaired persons. The results from the pilot study confirmed that the instructions and questions in the diary were understandable for the participants, the time for the task itself was not too long for the participants to sustain, and the diary provided appropriate information for the study aims.

The hearing-impaired participants were also requested to provide information of their daily hearing aid use and situations where they avoided using their hearing aids. The participants answered the four questions about their daily soundscape in the diary during 14 days. They 
were not required to complete the diary during 14 consecutive days but for 14 days during a maximum of a three-week period. In answering the questions the participants were asked to provide as much detail as possible and if there were days during the 14 days period when the participants did not perceive annoying sounds, they were asked to note this in the diary. When completed, the diary was returned by mail for analysis. The diaries were encoded with a number and the only information related to the diaries were the age (below or above 65 years), gender, pure-tone-average hearing thresholds (PTA4), signal processing (simple or advanced), and hearing aid experience (experienced or non-experienced).

To ensure that none of the participants was oversensitive to high-level sounds, all participants complete the Weinstein questionnaire of sound sensitivity (Weinstein, 1978). This questionnaire consisted of 20 items; 19 were statements about the sound environment and the last item was a self-rating of sound sensitivity. The result of the Weinstein questionnaire indicated a person's sound sensitivity related to the normal population. The participants were requested to answer the questions in relation to the aided situation. None of the participants in this study failed the Weinstein questionnaire.

\section{Analysis}

Based on the work of Graneheim \& Lundman (2004) a content analysis ${ }^{3}$ was performed of the diary data. The aim was to identify the sounds perceived as annoying and how many hearing aid users that found these sounds annoying in their daily soundscape. The frequency of occurrence of the annoying sounds during the study period was also noted. The content analysis was performed in three steps where the process of analysis involved steps back and forth between the whole and the details of the answers in the diaries. First, all of the diaries

\footnotetext{
${ }^{3}$ Content analysis originally emerged during the 1950ies in order to find objective, systematic and quantitative descriptors of communication. Content analysis is a method of interpreting text data, such as diaries, in a structured way and is used for both quantitative and qualitative research (Graneheim \& Lundman, 2004).
} 
were read for a holistic understanding of how the participants described annoying sounds in their soundscape. A primary categorization of sound types was made in relation to what the participants mention. From this first review of the diaries 14 primary categories of annoying sounds were defined. Second, each diary was read thoroughly where every comment was studied in detail. One way of interpreting data in a content analysis is to consider every comment in the data as a "meaningful unit", carrying information about the studied area. In the present work, every answer and comment was seen as a meaningful unit containing information about a sound or a sound source that the participant found annoying. The sound sources in the diaries were not always equally described, so every meaningful unit was condensed to give information of the sound and/or sound source that was mentioned. All of the comments in the diaries were condensed in this way. These condensed meaningful units were then categorized, counted, and ranked. In a third step those condensed meaningful units were compared with the 14 primary categories. A thorough reading of the diaries and the condensed meaningful units resulted in a final categorization that ultimately consisted of 18 sound categories.

The categorization according to the content analysis was done by two persons, the first author and an independent external reader experienced in content analysis. The categorization of the sounds was conducted independently by the two readers and the few sound source categorization that differed between the two readers, were re-analysed to consensus collectively. The following is an example to clarify how the analysis was conducted. The question about what sound/sound source that was annoying (question 1) gave this comment in one diary: "The sound when I take glasses and plates out of the dish washer, it clinks" (translation from Swedish). This comment was in the second step condensed to sounds from porcelain, and in the third step categorized as domestic sound, porcelain and cutlery. 
The categorized sounds were counted, first for every single diary and then for the whole group, for frequency and number of participants that mentioned a specific sound category. The categorized sounds were counted once every time they occurred, i.e. the same category was counted several times a day for the same participant if it was mentioned several times a day in the diary. The same procedure of counting was conducted when the participants were grouped in relation to gender, age, hearing loss, hearing aid experience, and type of signal processing. This was done to visualize differences, if any, between groups of noted annoying sounds. Statistical differences between the groups were calculated with chi2-tests and p-levels less than 0.05 were considered statistically different.

The study was approved by the Ethical Research Committee at Örebro County Council and no reimbursements were made to the participants. 


\section{Results}

The results were based on the answers from 60 hearing-impaired persons where none was considered oversensitive to sounds according to the Weinstein questionnaire.

\section{Hearing aid usage}

All of the participants used their hearing aids frequently, and, in total, the hearing aid usage was on average 11 hours per day (range 2-16 hours); 58\% of the participants used their hearing aids more than 10 hours per day - on average 14 hours per day. The remaining $42 \%$ of the participants used their hearing aids on average 6 hours per day. The data showed that the elderly (over 65 years) used their hearing aids significantly more frequently $(p<0.05)$ than the younger group; $80 \%$ of the elderly participants used their hearing aids more than 8 hours per day compared to $55 \%$ of the younger participants. The participants also noted that the hearing aids were not used in situations where they did not provide enough benefit or when annoying sounds were expected. Those predictions arose from previous experience of such situations. As one participant stated from his weekly dance course: "At the dance, the music from the CD-player, it jars upon my ears, I cannot use the hearing aids and it makes it difficult when I need to hear the coach." (Translation from Swedish).

The specific reason for not using the hearing aid for the whole day varied, but mostly stated to be due to lack of perceived benefit when at home or alone (55\%). The reasons given for not using the hearing aid at home were either that there was no sound or that they performed actions of high sound levels, e.g. vacuum cleaning. Other occasions when they decided to go unaided were for example when driving, taking a bath, or in windy situations. 


\section{Annoying sounds}

According to the content analysis of the data, 18 main categories for annoying sound sources were identified. These 18 categories were described and exemplified in Table 2. During the 14-days period the 60 participants noted 1018 occasions of annoying sounds when using hearing aids. The notations varied between once a fortnight to daily notations and the participants had an average of 17 notations per person of annoying sounds during the study period. The distribution of notations among the participants varied from 0 to 80 notations for the whole period (figure 2). The variation in number of notations can in part be explained by how the participants made the notations in the diary. The person with 80 notations seemed to strictly report every single occasion of annoyance, i.e. if the TV sound was annoying twice a day the person made two notations, while other participants just mentioned a sound source once a day even if it was likely that it occurred as annoying several times the same day. However, the number of notations were also a result of how often the different participants encountered annoying sounds. 
Table 2. The result for the whole group, ranked according to number of persons mentioning every sound category. The description of the categories of annoying sound based on the content analysis of the diaries. The table shows the number of notations for every category of annoying sounds as well as the number of participants who have mentioned that specific category of annoying sound.

\begin{tabular}{|c|c|c|c|}
\hline & & Whole gr & $(n=60)$ \\
\hline $\begin{array}{l}\text { Stated annoying sound } \\
\text { or sound source }\end{array}$ & Description & $\begin{array}{c}\mathrm{Nr} \text { of } \\
\text { notations }\end{array}$ & $\begin{array}{c}\text { Nr of } \\
\text { persons }\end{array}$ \\
\hline Verbal human sounds & $\begin{array}{l}\text { Sounds produced by people, verbal. An example of } \\
\text { these sounds is murmuring. }\end{array}$ & 157 & 33 \\
\hline TV/Radio & $\begin{array}{l}\text { Sounds emitted from the loudspeakers of TV and/or } \\
\text { radio }\end{array}$ & 176 & 25 \\
\hline Vehicles & $\begin{array}{l}\text { Sounds produced by vehicles with engines as cars, } \\
\text { trains, motorcycles etc. }\end{array}$ & 111 & 22 \\
\hline Machine tools & Sounds produced by e.g. power saw, drilling-machine. & 76 & 20 \\
\hline Household appliance & $\begin{array}{l}\text { Sounds produced by ordinary household appliances such } \\
\text { as washing machine, vacuum cleaner or electric mixer. }\end{array}$ & 82 & 20 \\
\hline Natural sounds & $\begin{array}{l}\text { Sounds typically heard in the open, e.g. wind, walking } \\
\text { on gravel, etc }\end{array}$ & 81 & 19 \\
\hline $\begin{array}{l}\text { Domestic sounds, } \\
\text { porcelain and cutlery }\end{array}$ & $\begin{array}{l}\text { Sounds from typical situations in the kitchen when } \\
\text { preparing dinner, setting the table or when eating. }\end{array}$ & 77 & 17 \\
\hline Music & $\begin{array}{l}\text { Both live music and music played in high fidelity } \\
\text { system }\end{array}$ & 26 & 16 \\
\hline $\begin{array}{l}\text { Non Verbal human } \\
\text { sounds }\end{array}$ & $\begin{array}{l}\text { Sounds produced by people, non-verbal sounds. } \\
\text { Examples of these sounds are coughing, laughter, etc }\end{array}$ & 17 & 10 \\
\hline Telephone & $\begin{array}{l}\text { Sounds emitted when speaking in the telephone, } \\
\text { and the telephone signal }\end{array}$ & 51 & 9 \\
\hline Rustling sounds & $\begin{array}{l}\text { Rustling sounds from plastic bags, paper, } \\
\text { and newspapers }\end{array}$ & 42 & 9 \\
\hline Background noise & $\begin{array}{l}\text { Sounds where the informants are unable to specify the } \\
\text { sources and only mention it as background noise }\end{array}$ & 23 & 8 \\
\hline $\begin{array}{l}\text { Domestic sounds, } \\
\text { running water }\end{array}$ & $\begin{array}{l}\text { Sound from running water in the household. Examples } \\
\text { are running water when doing the dishes } \\
\text { or when cleaning the house or in the bathroom. }\end{array}$ & 48 & 8 \\
\hline Impulsive sounds & $\begin{array}{l}\text { Sounds with high level and short duration. In this } \\
\text { category are for example hammer-blow and rifle shot } \\
\text { mentioned }\end{array}$ & 26 & 7 \\
\hline Speaker system & PA systems used for example at train stations & 5 & 5 \\
\hline Combined sounds & $\begin{array}{l}\text { Sounds from many sources which cannot be separated } \\
\text { in the analysis }\end{array}$ & 6 & 3 \\
\hline Office machines & $\begin{array}{l}\text { Sounds produced by machines used in ordinary office } \\
\text { work; } \\
\text { computer, printer, copying machine etc. }\end{array}$ & 12 & 2 \\
\hline Ventilation & Sounds from ventilation in buildings & 2 & 1 \\
\hline $\begin{array}{l}\text { Total number of } \\
\text { notations }\end{array}$ & & 1018 & \\
\hline
\end{tabular}




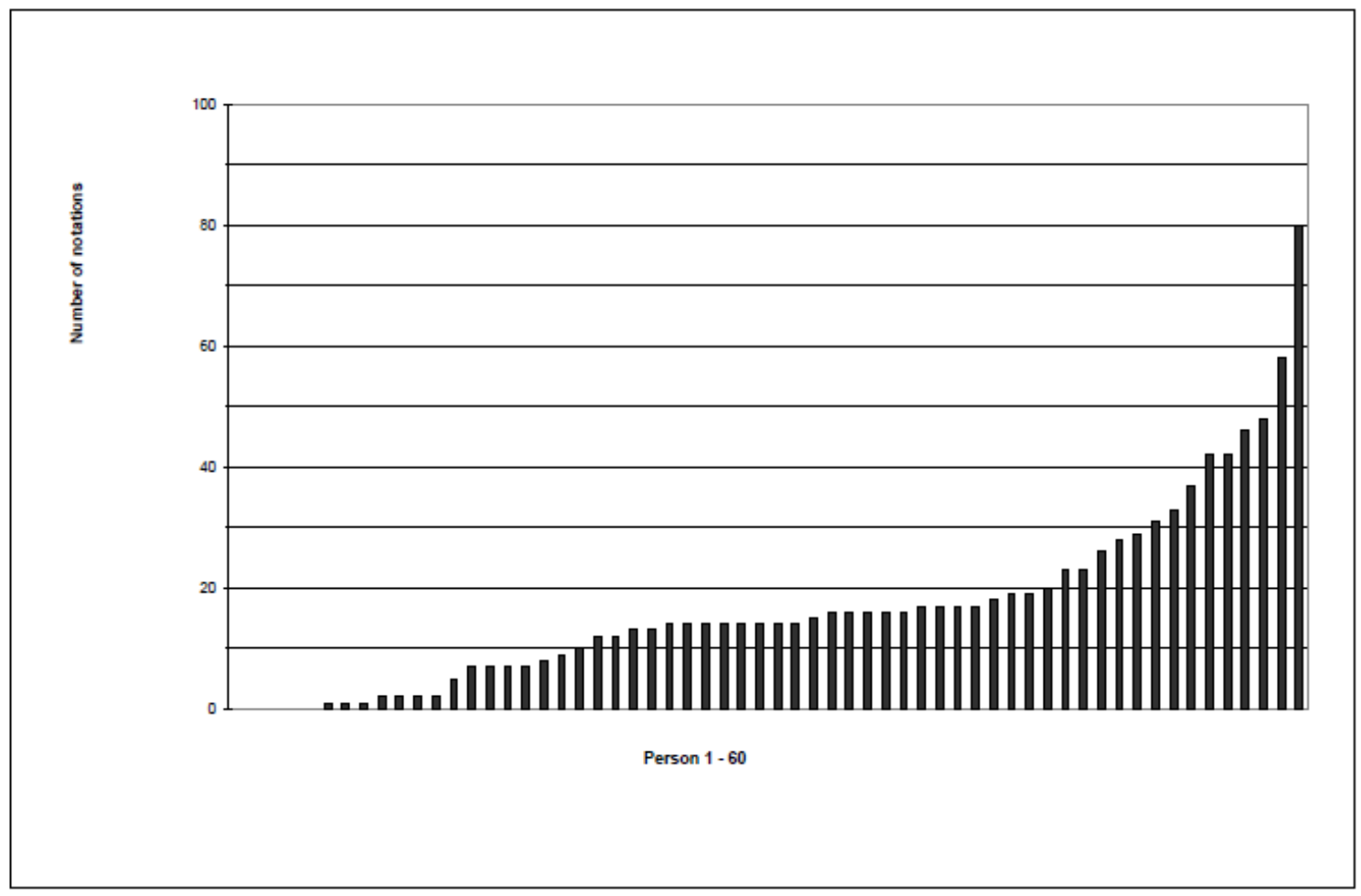

Figure 2: Distribution of made notations for the 60 hearing impaired participants.

The result in Table 2 is presented as the number of the participants who mention a specific type of sound and the total number of notations every annoying sound type caused. No grading of the annoying sound was provided, only information that a sound was regarded as annoying.

The analysis of the diaries showed clearly that hearing aid users experienced annoying sounds in their daily soundscape and there were many common sounds that cause annoyance. The result of the content analysis for the whole group is presented in Table 2 where verbal human sounds were the most often mentioned annoying type of sound (it was mentioned by $55 \%$ of the participants). According to the notations in the diaries verbal human sounds were annoying in two ways; either as (1) informative annoyance where the verbal sounds masked 
wanted sounds, or as (2) pure acoustical annoyance. Acoustical annoyance could be exemplified by a participant who notes "person with squeaky voices, it jars through my ears" (translation from Swedish). Another participant exemplified the informative annoyance with: "It is so annoying when all at the table are talking at the same time, I cannot hear what they are saying" (translation from Swedish). The second most mentioned annoying sound was TV/radio (42\%), where a common notation was the annoyance caused by the fluctuating sound level between speech and music or program and TV commercials. These two sound categories, verbal human sounds and television/radio, were mentioned most often and were the two sound sources that caused most notations for the whole group of participants. Following these two, the third to fifth most mentioned annoying sound sources were vehicles, household appliances, and machine tools.

When the data were analyzed according to the participants' age, hearing loss (PTA4), gender, hearing aid experience, or signal processing, the result was slightly different. Verbal human sounds were the most frequently mentioned annoying sound for all groups but the sounds mentioned thereafter differed between groups. There were only a few differences between the groups that were significant $(\mathrm{p}<.05)$. The result below is presented for those sound categories where significant differences were found.

The participants were subgrouped into three groups according to PTA4 of the better ear: 1) PTA4 less than $40 \mathrm{~dB}$ HL (31 persons), 2) PTA4 between 40 and $50 \mathrm{~dB}$ HL (18 persons), and 3) PTA4 more than $50 \mathrm{~dB}$ HL (11 persons). According to this division of the participants, the verbal human sound category was mostly mentioned as annoying by the subgroups with mild to moderate hearing losses while those with PTA4 > 50 dB HL mostly mentioned vehicles as annoying with verbal human sound and household appliances as the second and third 
category, respectively. For the participants in the two groups with PTA4 of less than $50 \mathrm{~dB}$ HL the category of TV/Radio sound was the second most mentioned annoying sound. The same result was obtained if the analysis was done according to the participants' worse ear ${ }^{4}$. No statistical significant differences were found between groups when the analysis was based on the participants' better ear but when the data were analysed for the worse ear a statistical significant difference was found in one category, non-verbal human sounds ( $p<0.01)$. Those with PTA4 between 40 - $50 \mathrm{~dB}$ HL did mention the non-verbal human sound more often as annoying compared with the two other subgroups.

When the group of participants was divided in a younger group ( $<65$ years, 20 persons) and an elderly group (>65 years, 40 persons) the verbal human sounds were the most mentioned annoying sound in both groups. In the younger group, the three categories most mentioned were (1) verbal human sounds, (2) natural sounds, and (3) TV/radio sounds, while the elderly group mentioned (1) verbal human sounds, (2) vehicles, and (3) TV/radio sounds as most annoying. Significant differences between the older and the younger groups were only found for non-verbal human sounds and for vehicles. Both these sound categories were mentioned more by the elderly than the younger participants. On average, the younger group had more notations per person (19/person) than the elderly group (16/person).

The participants were also divided based on gender, female (21 persons) and male (39 persons). The female group made notations more frequently (24/person) than the male group did (13/person). The result for the female and male group showed significant differences for four sound categories. These were non-verbal human sounds, television/radio, background

\footnotetext{
${ }^{4}$ When subgrouping according to worse ear the numbers in the three groups were: better than $40 \mathrm{~dB}$ HL (15 persons), 40 to $50 \mathrm{~dB}$ HL (28 persons), and worse than $50 \mathrm{~dB}$ HL (17 persons).
} 
noise, and porcelain and cutlery which were mentioned more often by the female group than by the male group.

The notations in the group of experienced users (43 persons) were similar to the whole group where verbal human sounds were followed by television/radio, vehicles, household appliances, and machine tools. In the group of non-experienced users (17 persons), an equal number of participants mentioned mostly television/radio and verbal human sounds; thereafter an equal number of participants mentioned porcelain and cutlery, natural sounds, and nonverbal human sounds. However, the differences between the two groups were not statistically significant.

Finally, the participants were divided in relation to signal processing in the hearing aid, simple (38 persons) and advanced (22 persons). Significant differences were found between simple and advanced signal processing for human sounds, both verbal and non-verbal, and for vehicles. The result indicated that verbal human sounds and vehicles annoy more persons using simple signal processing than those who used advanced signal processing. Otherwise, there were no statistically significant differences of mentioned annoying sounds between users of simple or advanced signal processing.

Five participants reported that they never experienced any annoying sounds during the 14 days they made notations in the diaries. They were all men aged between 60 and 83 years, both experienced and non-experienced hearing aid users, and they used both simple and advanced signal processing. The degree of hearing loss was evenly dispersed between 23 and $78 \mathrm{~dB}$ HL (PTA4). No explanation was found why these five men differed from the rest and did not experience annoying sounds. 


\section{Action when exposed to annoying sounds}

In the diary the participants were asked to describe their actions when exposed to annoying sounds. According to their answers, the most common action among the participants was to turn off or to remove the hearing aids. The information in the diaries did not reveal the duration of this action. Removing or turning off the hearing aids were primarily used in cases where the sound source was continuous or predictable. Examples of such events were driving, vacuum cleaning, or flushing water. Several note that there was a fear of losing information and participation in these situations. A typical example of this was a woman who, together with a friend, was attending a concert. Before the concert, waiting in the foyer, the person removed the hearing aids because of all annoying sounds even though she became unable to hear her friend.

Another action in case of annoying sounds was to try to accept the sound or cope with the situation; these actions were common when there was a sound of short duration or when it was inconvenient to remove the hearing aid. The actions were based on the participants' prior knowledge of the annoying sound and/or its duration. Other reasons for trying to cope with the sound were activities requiring the use of hearing aids. This could be exemplified with the following. A couple had a discussion in the kitchen while the wife was doing the dishes. She let the water flow and the husband tried to cope with the annoying sound in order to hear his wife. In such cases, greater effort was required by the hearing aid user to perceive the desired sound; this caused a sense of fatigue. 


\section{Discussion}

The aim of this study was to obtain a better understanding of the type of sounds within a daily soundscape that were perceived as annoying by hearing aid users, considered as successfully rehabilitated. The daily soundscape, as a concept, study the totality of sound phenomenon a person is exposed to (Schafer, 1994). Such soundscape include pleasant as well as annoying sounds. For a person with hearing impairment, the annoying sounds within the soundscape can be problematic due to perceptual negative consequences of the hearing loss, especially in adverse conditions or situations with high level sounds (Killion, 1993). Moreover, previous studies have shown that the perception of sound is different in a laboratory environment compared to real life (Kawai \& Yano, 2002). Therefore, in this study it was important to obtain a subjective description of the hearing aid users' experience in their daily life, and a field study was used as method.

The current method using a diary requires the participants to devote time every day and to be aware of the soundscape in a structured way they are not used to. This might be a reason why many of the invited persons rejected to participate in the study. Another reason for not participating could be that the invited hearing aid users did not experience annoying sounds and therefore found themselves unsuitable for the study. This might bias the study toward more experiences of annoying sounds than the general population of hearing aid users. However, the participants varied largely in number of annoying sounds noted (Figure 2) and some persons did not even experience annoying sounds. We therefore argue that the sample of participants is representative for the hearing aid users rehabilitated at the audiological clinic, Örebro university hospital. 
No participants below the age of 40 years participated in the study and there are probably two primary reasons for the problem finding younger persons to join the study. First, the sensorineural sloping hearing loss is more common among older than younger persons; this type of hearing loss was one of the inclusion criteria. Second, younger people are in a phase of life where family and work demand most of their time and they may not have prioritized participation in the current study. This lack of younger participants gave a slightly skewed age distribution. However, this age distribution corresponds rather well with the age distribution of hearing aid patients at the audiological clinics.

Although the participants were all patients at the same audiological clinic, there was a variety of hearing aids used in the study ( 8 manufacturers, 23 different types of hearing aids, Table 1). The categorization of the hearing aid signal processing was either simple or advanced. This was a rough categorization and modern hearing aids provide various noise reduction algorithms that may influence the perception of annoying sounds. However, noise reduction algorithms in hearing aids were not the focus of the study. Therefore, a broader categorization to investigate if there were differences between more and less advanced hearing aids was deemed sufficient.

Since a large part of the annoying sounds fall into the category of loud sounds another way to investigate the influence from the hearing aids would have been to categorize the hearing aids according to the gain at high input levels. This could have given information to what extent the gain at high level inputs affected the perception of annoying sounds. Unfortunately, this information was not available and solely categorize the hearing aids according to their high level gains could be unwise since annoyance was perceived for low level sounds as well. Moreover, impulse-like sounds have short rise times reaching the high-level peaks. Such 
impulse sounds may not reduce the hearing aid gain fast enough ${ }^{5}$ to affect the perceived sound level; this is unrelated to the gain at high levels. However, due to the time delay required for the signal processing, a transient detection and reduction is technically possible and is also implemented in some modern hearing aids (DiGiovanni, 2011). Consequently, although not optimal, the categorization of simple and advanced signal processing served the aim of the current study.

Most of the participants had used their hearing aids for a substantial time and had achieved experience from several situations where their hearing aids were more or less successful in providing benefit. According to comments given in the diaries, this had the consequence that in certain situations, varying between the participants, they chose not to use their hearing aids. This was a way to avoid sounds that would otherwise cause annoyance. Such behaviour may have affected the result since, when the hearing aids were not used, sounds were not reported that would have been perceived as annoying with active hearing aids.

All the participants were supplied with bilateral hearing aids but twelve of the participants only used one aid. During the rehabilitation process all participants were encouraged to use bilateral hearing aids; the reasons for unilateral hearing aid usage were not investigated since that was beyond the focus of the study. However, some of the hearing aid users explained that they did not achieve benefit enough with bilateral fittings and preferred to only use one hearing aid. It was not investigated if annoying sounds were the reason for unilateral hearing aid use, but there were no such indications in the diaries.

\footnotetext{
5 The attack time for the gain control in a hearing aid is often in the order of 10 to $40 \mathrm{~ms}$ while the rise time for impulse like sounds are often below $1 \mathrm{~ms}$.
} 
According to the notations, the overall most annoying sounds were human sounds and sounds emitted from machines. The notes in the diaries indicated that a great variety of machines were highly ranked as annoying due to acoustical annoyance, while human sounds were ranked as annoying because of the sense of lacking participation in the social context. The results in this study on persons with hearing impairment were different compared to persons with normal hearing according to previous studies (Botteldoren et al, 2006). However, the pilot study that was conducted on young participants with normal hearing prior to the here reported study indicated similar results between hearing impaired and normal hearing subjects. No in-depth analysis was performed between the results from the normal hearing and hearing impaired participants because of the differences (age, gender and number of subjects) between the study group and the pilot study group.

Another way to analyse the data in the present study would be to investigate the average frequency of the occurrence for each person, i.e. number of notations divided by number of persons experience that sound. According to such analysis of Table 2, TV/Radio would be the most annoying sound with a ratio of 7.04 followed by Running water (Domestic sounds) and Office machines, both with a ratio of 6.00. The problem using such approach is that although Office machines were the second most annoying sound, it was only experienced by two subjects. Consequently, if one or a few subjects experience a particular sound as very annoying, but that same sound was not perceived as annoying by others, it can still be assessed as a very annoying sound in that type of analysis. Therefore, we argue that the chosen way of analysing the data in this study provides a better insight to sounds perceived as annoying by hearing aid wearers. 
When analysing the participants' descriptions in the study, the annoyance was based both on sound levels and spectral pattern. As pointed out previously, annoyance based on high-level sounds could originate in the hearing aid settings; especially the gain at high input levels would influence the perceived annoyance for high-level sounds. The hearing aid setting is a compromise between improved speech understanding, primarily through audibility, and reducing annoying sounds. One can argue that there might be maladjustments of the hearing aids at the present clinic since some of the participants complained about high-level sounds. However, complaints of high-level sounds is not unique to the current clinic and similar problems are reported worldwide with modern hearing aids giving negative effects and problems when coping with environmental sounds (Johnson et al, 2010, Kochkin, 2010). The MarkeTrak studies have shown a reduction in the amount of hearing aid non-use, from $17.9 \%$ in 1994 to $12.4 \%$ in 2008 (Kochkin, 2010), indicating that comfort and benefit problems with hearing aids still remains. During the same time the satisfied hearing aid users increased from $53.5 \%$ to $74.0 \%$ indicating that improvements of hearing aids (and to some extent, the fitting) have increased hearing aid benefit. However, some users (26\%) are still dissatisfied with their hearing aids (Kochkin, 2010). I should be noted that even though most hearing aid wearers experience annoying sounds, only a minority is dissatisfied with the sound quality in the hearing aids.

After the study the participants were encouraged to contact the audiologic clinic for adjustments if needed. Within one year after the study, nine persons had contacted the clinic for hearing aid adjustments. These problems should have been handled during the hearing aid fitting; objective measurements of uncomfortable levels could have reduced the annoyance perceived at high-level sounds of longer durations. However, the main focus for the rehabilitation of hearing impaired persons in the current clinic, similar to most hearing clinics, 
is to improve auditory communication. The current clinic has adopted the COSI method as a tool to improve the individual patient's auditory communication (Dillon et al, 1997); all the participants had a successful rehabilitation according to this scale. Although the rehabilitation was considered successful with the COSI instrument, nearly all experienced annoyance using their hearing aid at some situations. Consequently, even if the participants were to some extent evaluated for loud and uncomfortable sounds during the fitting process (see methods section), the finding that nearly all experience annoying sounds in their daily soundscape implicate a need for different approaches in the rehabilitation process. Unfortunately, this study does not give a basis for how such management should be designed, and, as has been pointed out in previous studies, there is a need of more and thorough studies of annoying sounds and the rehabilitation process.

As stated previously, the perception of annoying sounds can be characterized as either informatively annoying or acoustically annoying sounds. It could be understood from the context of the notations in the diaries if the participant perceived a sound as informatively or acoustically annoying. The notations also indicated that the perception of the annoyance depended on the possibility to influence or control the annoying sound. It was previously shown that the possibility to control a sound source was of great importance for the degree of annoyance (Maris et al, 2007). Consequently, a limitation in the ability to influence the surroundings can affect the ability to cope or endure annoying sounds. Moreover, a reduced capacity to endure annoying sounds may also be due to impaired auditory function (hearing loss) resulting in abnormal loudness perception, increased masking, and impaired frequency resolution reducing the speech perception in adverse situations. 
The participants experienced and noted the annoying sounds differently. Some participants regarded one sound as annoying every day while others just noticed the same type of sound occasionally. There are probably several reasons for this difference: the sound may have occurred with different frequency in the different participants' environment, or it was only judged as annoying in some specific situations. The result is presented as the number of the participants that mentioned a specific type of sound. A drawback with this method is that the sound itself is not quantified in terms of the annoyance. One example is the annoyance some participants experienced at the dentist. The sound of drilling was commented as very annoying for those who, during the 2-week period, had a dentist appointment. In the result this sound is categorized as a machine sound and counted as one of those. Since dentist appointments occur occasionally for a person, it is only a few participants that have the possibility to mention this specific sound source in their diary. Sound sources with few occurrences were categorized into a broader definition of sounds. If the number of participants had been greater or duration of diary notation longer, more specific categorization could have been made. That might have resulted in better understanding of what sound sources hearing aid users experience as annoying.

Figure 2 presents the relationship between participant and number of notations during the study period. This was made to divide the group into light-complainers and heavycomplainers. The distribution of notations is evenly dispersed between zero and 80 notations. However, no difference between light and heavy complainers could be found that provided new information. Worth noticing is that the person with 80 notations is not, according to the Weinstein formula, particularly sensitive to sounds. Also, the number of notations varies during the two-week period of data collection. This variation depends on the exposure to situations and soundscapes where annoying sounds occur. There might also be a variation of 
how industrious the participant is in taking notes. It seem safe to assume that the degree of social activity and the number of acoustic environment a subject confront each day influence the number of notations made. Consequently, the division based on figure 2 may not be the most appropriate way to investigate heavy and light complainers.

A very interesting question regarding the results from the subgroups is the origin of the differences obtained. Are these differences a result of different perception of the various sound sources or are they expressions of interest and familiarity to the sounds? One example of this is in the female and the male groups, where the males mention the vehicles more often than the females, while the females more frequently mention television/radio as annoying. One can hypothesize that men are more exposed to vehicle sounds and therefore more frequently note them as annoying; the same reasoning is not equally clear for the female group mentioning television/radio as annoying. This study cannot decisively explain these types of differences.

In order to correctly describe a soundscape the description cannot solely rely on either perceptual or acoustical (physical) notations but requires both dimensions, as well as the connection between them (Raimbault et al, 2003). The present study was focused on analysing the perceptual descriptions of participants' daily soundscapes, and finding differences, if any, between groups regarding age, degree of hearing loss, gender, hearing aid usage, and type of signal processing. As a consequence, the analysis focused on the type of sounds and the number of participants that found them annoying. Also, the actions made by the listeners to handle the situations were presented. In order to obtain a correct description of the soundscape it is of interest to investigate the annoying sounds more thoroughly and how the listeners perceive those annoying sounds, with and without hearing aids, to achieve a 
broader understanding of the origin and influence of annoying sounds. Sounds perceived as annoying are, as the result from this study indicates, not only based on the loudness or gain setting in the hearing aid. The most frequently mentioned sound for the participants is verbal sounds at different levels and situations. However, the annoyance problem can be reduced by a proper fitting where the gain is appropriately set for the input levels in each frequency band to ensure an acceptable listening situation for all environmental sounds. 


\section{Conclusions}

The diary method used in this study was shown to be a possible tool to obtain information about annoying sounds for hearing aid users in their daily soundscape. Information from the diaries indicated that hearing aid users find sounds in their daily soundscape annoying. The sound category most often reported as annoying was verbal human sounds, followed by TV/radio and vehicles. Few significant differences were found when subgrouping the hearing aid users in relation to age, degree of hearing loss, gender, hearing aid experience, and signal processing used in the hearing aids. This study indicates that there are sounds in a daily soundscape that are perceived as annoying and result in a decreased usage of the hearing aids. The method of the diary as used here was not able to target the origin of the annoyance, if it is caused by acoustical and/or psychoacoustical factors. Hence, there is a need of more thorough studies within the area of why the sounds are considered as annoying. It was also found that even though most of the participants were regarded as having a successful rehabilitation by the participants themselves as well as by the audiologist, the hearing aid users still experience annoying sounds in their daily soundscape. Consequently, although patients have had their hearing aids fitted according to clinical routine, the problem with annoying sounds call for more objective as well as subjective assessment of sound perception during the hearing aid fitting, especially for loud sounds. This affirms the need of studies of different management approaches within the rehabilitation process that consider the presence of annoying sounds. 


\section{Acknowledgement}

The authors would like to thank Kerstin Möller for assistance with the data analysis. We are also grateful to three anonymous reviewers and the section editor, William Noble, for valuable comments. 


\section{References:}

Alcantara, J.I., Moore, B.C.J., Kühnel, V. \& Launer, S. 2003. Evaluation of the noise reduction system in a commercial digital hearing aid. Int J Audiol, 42, 34-42.

Augoyard, J-F., Karlsson, H. \& Winkler, J. 1999. Report and resolution of the Soundscape Research Study Group. In: Karlsson, H (ed.), From Awareness to Action, Conf. Proceedings "Stockholm, Hey Listen!", Royal Swedish Academy of Music/World Forum for Acoustic Ecology, Stockholm, Sweden, 9-13 June 1998, 130-135.

Botteldooren, D., De Coensel, B. \& De Muer, T. 2006. The temporal structure of urban soundscapes. J Sound Vibr, 292, 105-123.

Buus, S. \& Florentine, M. 2002. Growth of loudness in listeners with cochlear hearing losses: recruitment reconsidered. J Assoc Res Otolaryngol, 3, 120-139.

Cox RM. \& Alexander GC. 1995. The abbreviated profile of hearing-aid benefit. Ear Hear $16,176-86$.

Cox, RM., Alexander, GC. \& Gray, GA. 2007. Personality, hearing problems, and amplification characteristics: contributions to self-report hearing aid outcomes. Ear Hear, 28, 141-162.

DiGiovanni, J., Davlin, E., \& Nagaraj, N. 2011. Effects of transient noise reduction algorithms on speech intelligibility and ratings of hearing aid users. Am J Audiol, 20, 140-150.

Dillon, H., James, A.\& Ginis, J. 1997. Client Oriented Scale of Improvement (COSI) and its relationship to several other measures of benefit and satisfaction provided by hearing aids. $J$ Am Acad Audiol, 8, 27-43.

Dillon, H. 2001. Hearing aids. Stuttgart: Thieme.

Dreschler, WA., Keidser, G., Convery, E., Dillon, H. 2008. Client-based adjustments of hearing aid gain: The effect of different control configurations. Ear Hear, 29, 214-227.

Gatehouse, S. \& Akeroyd, M. 2006. Two-eared listening in dynamic situations. Int J Audiol, 45, Suppl 1, S120-S124.

Gatehouse, S., Naylor, G., \& Elberling, C. 2003. Benefits from hearing aids in relation to the interaction between the user and the environment. Int J Audiol, 42, Suppl 1, S77-S85.

Gaver, WW. 1993. What in the world do we hear?: an ecological approach to auditory event perception. Ecological psychology, 5, 1-29.

Graneheim, U.H. \& Lundman, B. 2004. Qualitative content analysis in nursing research: concepts, procedures and measures to achieve trustworthiness. Nurse Educ Today, 24, 105112.

Guski, R., Felscher-Suhr, U. \& Schuemer, R. 1999. The concept of noise annoyance: how international experts see it. J Sound Vibr, 223, 513-527. 
Hallberg, L., Hallberg U. \& Kramer, S. 2008. Self-reported hearing difficulties, communication strategies and psychological general well-being (quality of life) in patients with acquired hearing impairment. Disabil Rehab, 30,203-212.

Hedfors, P. 2003. Site soundscapes. Landscape architecture in the light of sound. [Diss]. Uppsala: Swedish University of Agricultural Sciences.

Hernandez, A., Chalupper, J., \& Powers, T. 2006. An assessment of everyday noises and their annoyance. Hear Rev, 13 (7), 16-20.

Hällgren, M., Larsby, B., Lyxell, B. \& Arlinger, S. 2005. Speech understanding in quiet and noise, with and without hearing aids. Int J Audiol, 44, 574-583.

Johnson, JA., Cox, RM. \& Alexander GC. 2010. Development of APHAB norms for WDRC hearing aids and comparisons with original norms. Ear \& Hear, 31(1), 47-55

Kawai, K. \& Yano T. 2002. Relation between the overall impression of the sound environment and types and loudness of environmental sounds. J Sound Vibr, 250, 41-46.

Keidser, G., Convery, E., Kiessling, J., Bentler, R. 2009. Is the hearing instrument to blame when things get really noisy? Hear Rev 16(8), 12-19.

Keidser, G., O’Brien, A., Latzel, M. \& Convery, E. 2007. Evaluation of a noise-reduction algorithm that targets non-speech transient sounds. Hear J, 60(2), 29-39.

Killion, MC. \& Fikret-Pasa, S. 1993. The 3 types of sensorineural hearing loss: loudness and intelligibility considerations. Hear J, 46 (11), 31-36.

Kirkwood, DH. 2001. Most dispensers in Journals survey report greater patient satisfaction with digitals. Hear J, 54 (3), 21-32.

Kochkin, S. 2000. MarkeTrak V: "Why my hearing aids are in the drawer": the consumers' perspective. Hear J, 53 (2), 34-41.

Kochkin, S. \& Rogin, M. 2000. Quantifying the obvious: the impact of hearing instruments on quality of life. Hear Rev, 7 (1): 6-35.

Kochkin, S. 2005. Marke Trak VII: Customer satisfaction with hearing instruments in the digital age. Hear J, 58 (9), 30-43.

Kochkin, S. 2010. Marke Trak VIII: Consumer satisfaction with hearing aids is slowly increasing. Hear J, 63 (1), 19-31.

Linssen, AM., Joore, MA., Minten, R., van Leeuwen, Y. \& Anteunis, L. 2013. Qualitative interviews on the beliefs and feelings of adults towards their ownership, but non-use of hearing aids. Int J Audiol, 52, 670-677.

Maris, E., Stallen, PJ., Vermunt, R., et al. 2007. Noise within the social context: Annoyance reduction through fair procedures. J Acoust Soc Am, 121 (4), 2000-2010. 
Moore, BCJ. 2002. Psychoacoustics of normal and impaired hearing. Br Med Bull, 63, 121134.

Noble, W. 1983. Hearing, hearing impairment, and the audible world: a theoretical essay. Audiology, 22, 325-338.

Noble W \& Gatehouse S. 2006. Effects of bilateral versus unilateral hearing aid fitting on abilities measured by the Speech, Spatial, and Qualities of Hearing Scale (SSQ). Int J Audiol, $45,172-181$.

Palmer, CV., Bentler, R. \& Mueller HG. 2006 Amplification with digital noise reduction and the perception of annoying and aversive sounds. Trends in ampl, 10 (2), 95-104.

Raimbault, M., Lavandier C. \& Bérengier M. 2003. Ambient sound assessment of urban environments: field studies in two French cities. Appl Acoustics, 64, 1241-1256.

Raimbault, M.\& Dubois, D. 2005. Urban soundscapes: Experiences and knowledge. Cities, 22, 339-350.

Schafer, RM. 1994. The soundscape. Our sonic environment and the tuning of the world. Rochester: Destiny Books.

Schum, DJ. \& Pogash, RR. 2003. Blinded comparison of three levels of hearing aid technology. Hear Rev, 10 (1), 40-43,64-65.

Smeds, K., Leijon, A. 2000. Hörapparatutprovning. Bromma: CA Tegnér AB.

Smeds, K., Keidser, G., Zakis, J., Dillon, H., Leijon, A., Grant, F., Convery, E. \& Brew, C. 2006. Preferred overall loudness. II: Listening through hearing aids in field and laboratory tests. Int J Audiol, 45 (1), 12-25.

Turner, CW., Cummings, KJ. 1999. Speech audibility for listeners with high-frequency hearing loss. Am J Audiol, 8, 47-56.

Weinstein, ND. 1978. Individual differences in reactions to noise - a longitudinal study in a college dormitory. J Appl Psychol, 63, 458-466.

WHO. 2001. International Classification of Functioning, Disability and Health. Geneva: World Health Organization

Yang, W., Kang, J. 2005. Acoustic comfort evaluation in urban open public spaces. App Acoustics, 66, 211-229. 